\title{
Impact Test Applications Supported by Fea-Models in Surface Engineering for Coatings Characterization
}

\author{
Georgios Skordaris 1,* , Antonios Bouzakis ${ }^{2}$ and Konstantinos-Dionysios Bouzakis 1,3 \\ 1 Laboratory for Machine Tools and Manufacturing Engineering, Mechanical Engineering Department, \\ Aristotle University of Thessaloniki, Greece; skordaris@auth.gr, bouzakis@eng.auth.gr \\ 2 Impact-BZ Ltd. London, United Kingdom, info@impact-bz.com \\ 3 Turkish-German University in Istanbul, Turkey \\ * Correspondence: skordaris@auth.gr; Tel.: +303210996027
}

Received: 7 February 2020; Accepted: 30 April 2020; Published: 30 April 2020

\begin{abstract}
The impact test is used since several years, among others, for characterizing the fatigue strength, creep, adhesion and residual stresses of coatings at ambient and elevated temperatures under dry or lubricated conditions. A main advantage of this test method is that in many cases, it can be employed directly on the coated parts and not on specimens. The obtained experimental results are evaluated by convenient FEM supported algorithms. Based on these algorithms, critical data for predicting the life span of coated parts such cutting tools, bearing etc. and for planning appropriate replacements can be determined. The paper renders an overview about the development of impact test devices, experimental techniques and results evaluation methods. Characteristic examples highlighting the quantification of the fatigue strength of PVD coatings and their adhesion via a critical equivalent and shear stress respectively as well as of the temperaturedependent interfacial fatigue strength of diamond coatings via a critical shear stress are shown.
\end{abstract}

Keywords: impact test; coating; properties

\section{Introduction}

The surface properties of machine parts and elements strongly affect their operational reliability [1-3]. Therefore, methods to determine superficial material data after the final surface treatments are pivotal, since they facilitate to check the convergence to prescribed surface specifications required for the fulfillment of technical requirements [4-6]. Hereupon, the fatigue endurance of repetitively loaded surfaces is a significant property. To assess this property, the related surfaces must be loaded periodically under conditions similar to the parts' real operation. The surface response and wear during such a test must be monitored and appropriately analyzed for attaining characteristic material data related to the fatigue strength, residual stresses, adhesion (in the case of coated surfaces), etc..

The surface response of various materials can be investigated at various repetitive loads and impact times using impact test devices, as presented in the publications $[4,7,8]$. Using an electrodynamic impact tester, impact times less than $1 \mathrm{~ms}$ can be realized [7]. Furthermore, via a piezoelectric one, longer impact times than $1 \mathrm{~ms}$ can be adjusted [8]. Figure 1 illustrates the impact tester and the related fixtures for conducting perpendicular and inclined impact tests. This device was manufactured by the company Impact-BZ (London, UK) [9] in conjunction with the Laboratory for Machine Tools and Manufacturing Engineering of the Aristotle University of Thessaloniki. A ceramic ball of $5 \mathrm{~mm}$ diameter penetrates repetitively into the specimen under an adjustable maximum load. With the aid of a proportional, integral and differential (PID) controller, the output voltage of a variable transformer, through a direct current (DC) motor is adjusted to attain constant impact force peaks throughout the entire test duration. Moreover, measurements of current, forces, 
temperatures, and further process parameters are conducted and monitored. Employing this impact tester, various coating's properties at ambient or elevated temperatures can be characterized and related material data defined. In the next sections, relevant application examples will be presented as well as FEM supported procedures for evaluating the results and determining data such as the fatigue endurance stress and coating adhesion of PVD as well as of diamond coatings.

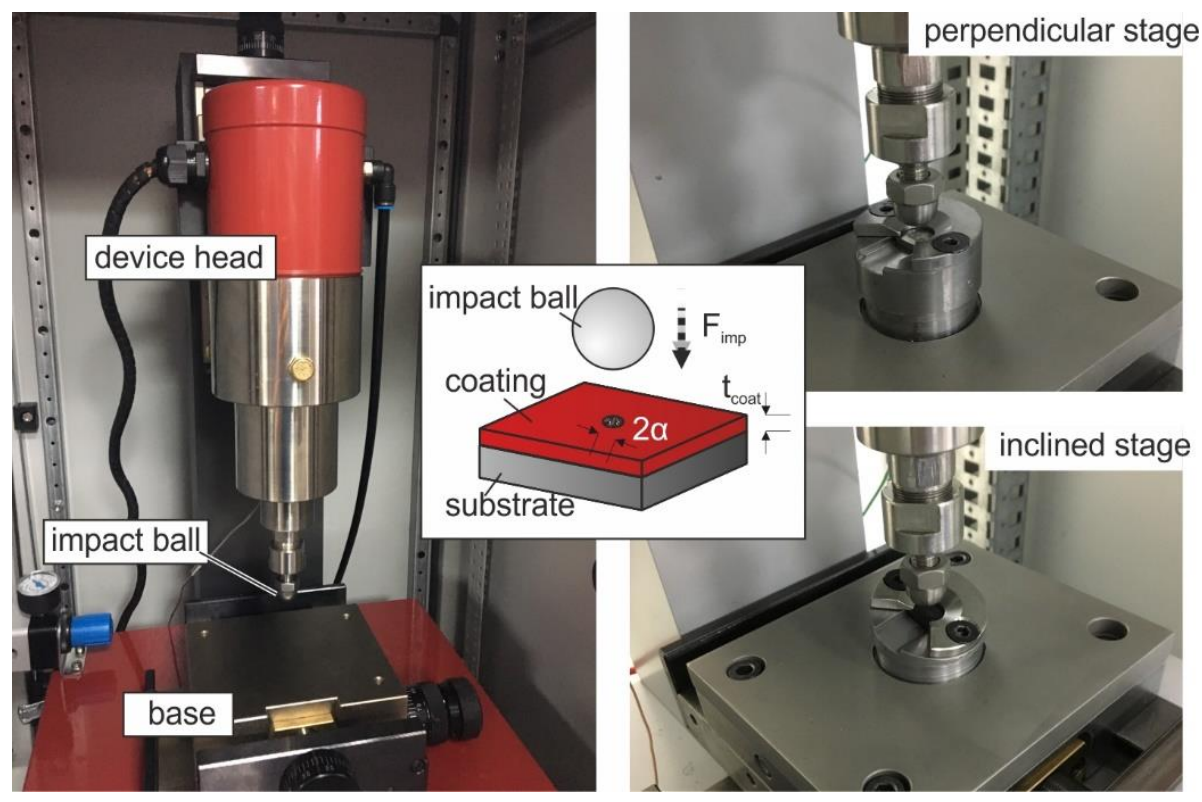

Figure 1. Impact tester and the related fixtures for conducting perpendicular and inclined impact tests.

\section{PVD Coating's Fatigue Strength and Adhesion}

\subsection{Methodology}

During the impact test a ball indenter penetrates periodically into the coating under a desired maximum load. Depending on the impact load and on the number of impacts, a coating failure may occur. The perpendicular impact tests aim at detecting the maximum impact force Fmax (fatigue threshold force) which the coating can withstand without failure. With the aid of a FEM simulation of the impact test, the maximum equivalent stress developed in the coating at the fatigue threshold force $F_{\max }$ during its loading and the remaining one due to the substrate plastic deformation is calculated. Based on these data, the Smith-like diagram illustrated in Figure 2 is established [4]. Via this diagram, the coating fatigue endurance stress $S_{D}$ for repetitive loads from zero up to a certain maximum value is determined. Considering $\mathrm{S}_{\mathrm{D}}$, the Woehler-like diagram demonstrated in the middle of Figure 2 is created. The data employed for establishing the aforementioned graphs do not depend on the coating adhesion, since the film is only vertically loaded during the perpendicular impact test.

The film adhesion can be characterized by inclined impact-test [10]. The oblique loading direction during the inclined impact test induces shear stresses into the film, which in the case of a poor adhesion leads to coating material overloading and to its accelerated failure [10]. This test also renders possible the PVD film adhesion quantification in terms of the tangential to normal filmsubstrate interface stiffness (CSR ratio). CSR equal to 1 means, that the film adhesion is ideal. In this context, employing a FEA model of the inclined impact test at an inclination angle $\theta$, the coating maximum stress $S_{F}$ induced by a force $F$ is calculated. In these calculations, an ideal adhesion $(C S R=1)$ is assumed. If the film-substrate adhesion is not ideal (CSR $<1)$, the coating strains are higher compared to the developed ones at the same load in the case of an ideal adhesion. Hence, the actual coating stress $S^{*}$ eqv is larger than $S_{F}$, thus leading to film fatigue failure at a smaller number of impacts $\mathrm{NI}^{*}$ than the expected $\mathrm{NI}_{\mathrm{F}}$ according to the established Woehler diagram (see Figure 2). The parameter $\mathrm{NI}^{*}$ is experimentally determined by conducting inclined impact tests. The Woehler diagram is 
employed, since due to the enhanced strength properties of the cemented carbide and the lower loads applied in the inclined impact test, the substrate plastic deformation is negligible and the remaining stresses too. If this is not valid, as for example in the case of softer substrates, the methods described in the publication [11] are used. Finally, by FEM supported calculations in the third procedure stage, the maximum equivalent stress $S_{\text {eqvi max }}$ developed at a force $\mathrm{F}$ and constant inclination angle $\theta$ is determined as a function of the CSR metric (see graph at the bottom of Figure 2). Using the latter graph, taking into account the determined actual coating stress $\mathrm{S}^{*}$ eqv, the CSR of the tested coating is graphically defined [12].

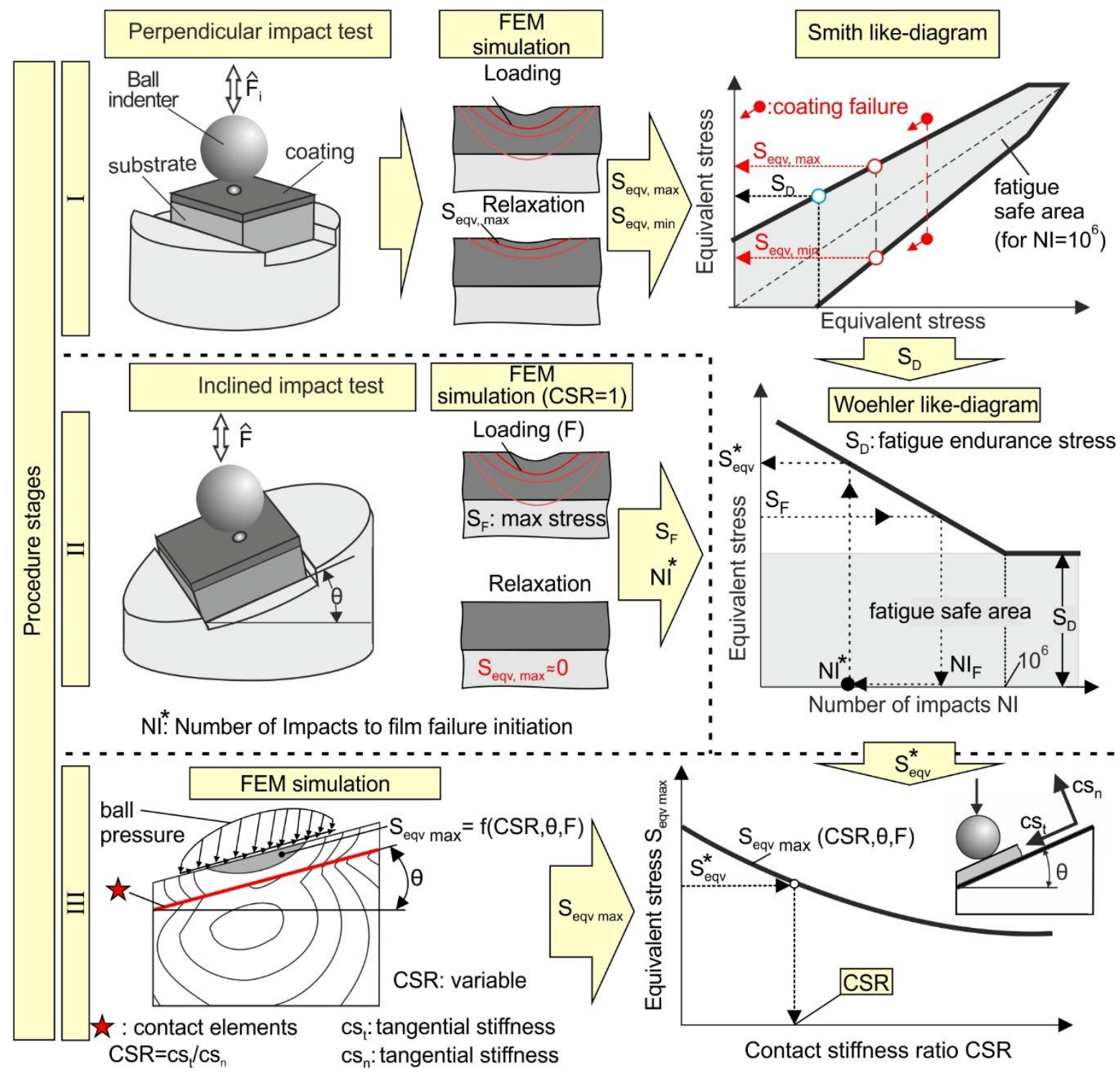

Figure 2. Experimental-computational procedures to determine the fatigue strength and the contact stiffness ratio (CSR) between coating and substrate.

\subsection{Characteristic Examples}

An example of the coating failure evolution during the perpendicular impact test is demonstrated in Figure 3 [12]. In this example, the applied impact load imposes maximum equivalent stresses during the loading and relaxation outside of the fatigue safe area of the film Smith-like diagram shown in Figure 3, thus causing a film fatigue fracture. The latter diagram schematically presented in Figure 2 (see procedures' stage I) is further described in the following. For capturing the remaining imprint depth RID, sections in the middle of the impact imprint were carried out using confocal microscopy. After $10^{4}$ impacts, RID amounts to approximately $0.2 \mu \mathrm{m}$. This corresponds 
roughly to the substrate plastic deformation induced by the applied impact load of $300 \mathrm{~N}$. At $10^{6}$ impacts due to the progressive crack propagation and the occurring film micro-damages and removal, an imprint depth of roughly $3.2 \mu \mathrm{m}$ develops. This is larger than the film thickness and thus, the substrate is revealed.

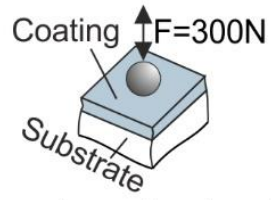

max. stress developed to coating $\mathrm{S}_{\text {eqv } \max }=3.1 \mathrm{GPa}$
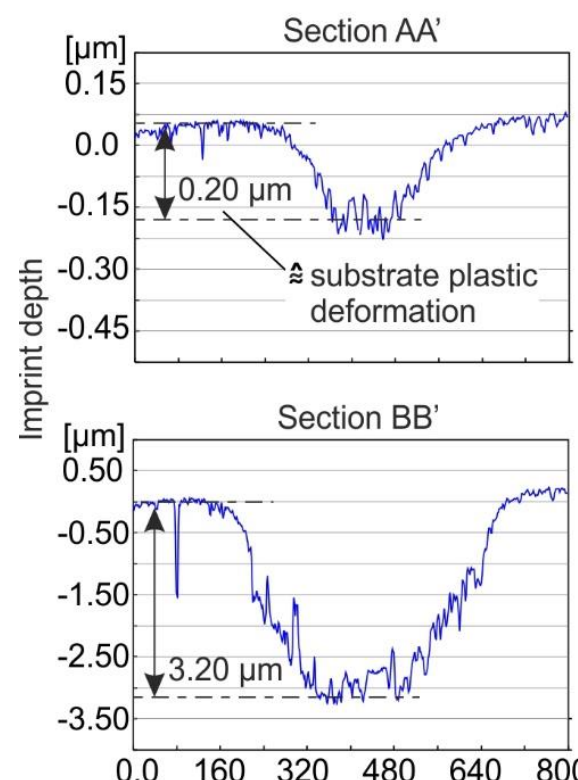

(1)
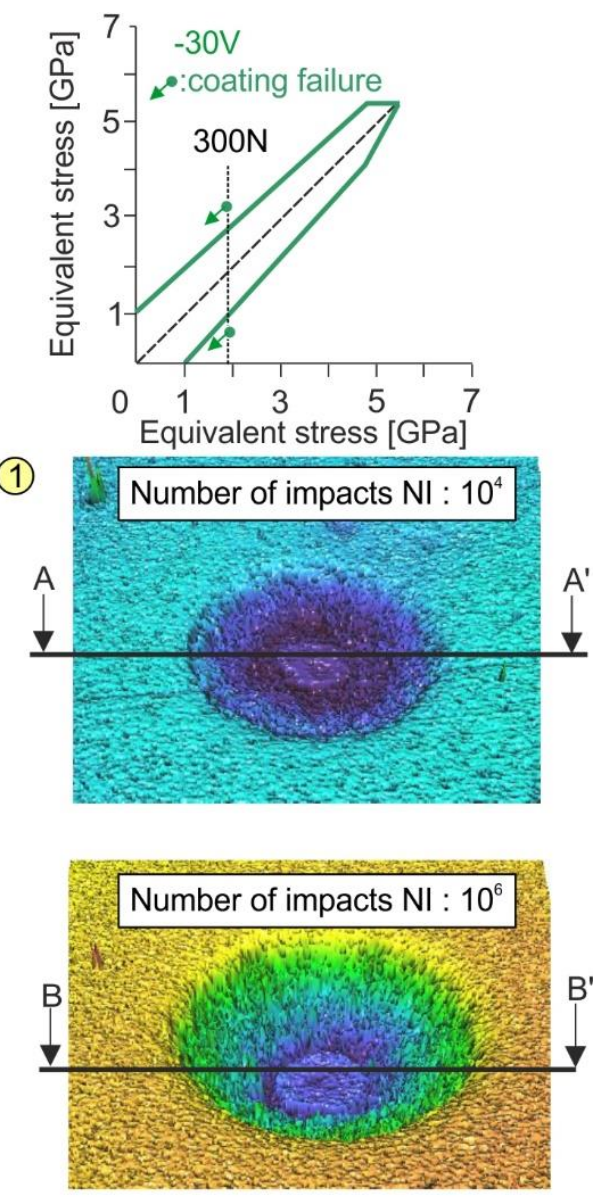

Substrate: Sandvik R245-12 T3, HW-K05

Coating: PVD TiAIN, bias voltage $=-30 \mathrm{~V}, \mathrm{t} \approx 3 \mu \mathrm{m}$

Figure 3. Wear evolution on a coating during the perpendicular impact test.

Using the FEM-supported simulation of the impact test mentioned in Figure 2a [12], the maximum equivalent stress during the impact test loading and relaxation at the force of $200 \mathrm{~N}$ and at the fatigue threshold loads of PVD TiAN coatings deposited at various bias voltage were calculated. Based on these data, as schematically depicted in Figure 2a, the Smith-like diagrams demonstrated in Figure 4a were established for the investigated coatings. Employing the latter graphs, the coating's fatigue endurance stresses $S_{D}$ for repetitive loading from zero to a maximum value were defined. Considering these stresses, the Woehler-like diagrams of the investigated coatings captured in Figure $4 \mathrm{~b}$ were established. These results show that the bias voltage augmentation increased the coating's fatigue endurance stresses.

Moreover, inclined impact tests were conducted for evaluating the adhesion of the aforementioned coatings [12]. To reduce the inclined impact test duration and simultaneously to achieve film removal rates enabling an efficient monitoring of the coating damage evolution, the impact load $\mathrm{F}$ and the inclination angle $\theta$ were adjusted to $90 \mathrm{~N}$ and $15^{\circ}$ respectively. The developed coating failure depth (CFD) versus the number of impacts on the coatings prepared at various bias voltages are presented in Figure 5a. The criterion for the coating fracture start was a coating failure depth CFD equal to $0.5 \mu \mathrm{m}$. At the applied inclined impact test conditions, if the film deposited at $-30 \mathrm{~V}$ had an ideal adhesion $(\mathrm{CSR}=1)$, the maximum equivalent stress in the coating would be approximately $2 \mathrm{GPa}$ according to conducted FEM-supported calculations. Since this stress is less than the corresponding fatigue 
endurance one of this coating amounting to $2.1 \mathrm{GPa}$, no film fatigue fracture after one million repetitive impacts would appear. However, because the film adhesion is not ideal $(\mathrm{CSR}<1)$ in the film case of $-30 \mathrm{~V}$ bias voltage, the coating fatigue fracture starts after approximately $4.5 \times 10^{5} \mathrm{impacts}$ $\left(\mathrm{NI}^{*}\right)$ whereas at multi bias voltage after roughly $\mathrm{NI}^{*} 1.3 \times 10^{5}$ impacts (see Figure $5 \mathrm{a}$ ). For determining the actual CSRs of the investigated films, the procedures' stage III clarified in Figure 2 was employed. More specifically, at the applied impact force of $90 \mathrm{~N}$ and inclination angle of $15^{\circ}$, the resulting maximum film equivalent stress $\mathrm{S}^{*}$ eqv versus CSR was described as a function of CSR as illustrated in the right-hand graphs of Figure $5 \mathrm{~b}$. The numbers of impacts $\mathrm{NI}^{*}$ associated with the coating fatigue fracture start were introduced in the corresponding Woelher-like diagrams exhibited at the right of Figure $5 \mathrm{~b}$ and the corresponding $\mathrm{S}^{*}$ eqv stresses were defined. Considering these stresses, as depicted in this figure, the related CSRs were defined amounting to 0.05 and 0.004 in the case of $-30 \mathrm{~V}$ and multi bias voltage, respectively. The attained results indicate that coatings deposited at higher bias voltages are associated with a significant CSR decrease. In this way, coatings deposited at the bias voltage of $-30 \mathrm{~V}$, although they possess lower fatigue strength compared to those ones deposited at multi bias voltage, demonstrate a comparably better performance in the inclined impact tests. This fact can be explained considering the adhesion deterioration when increasing the bias voltage.
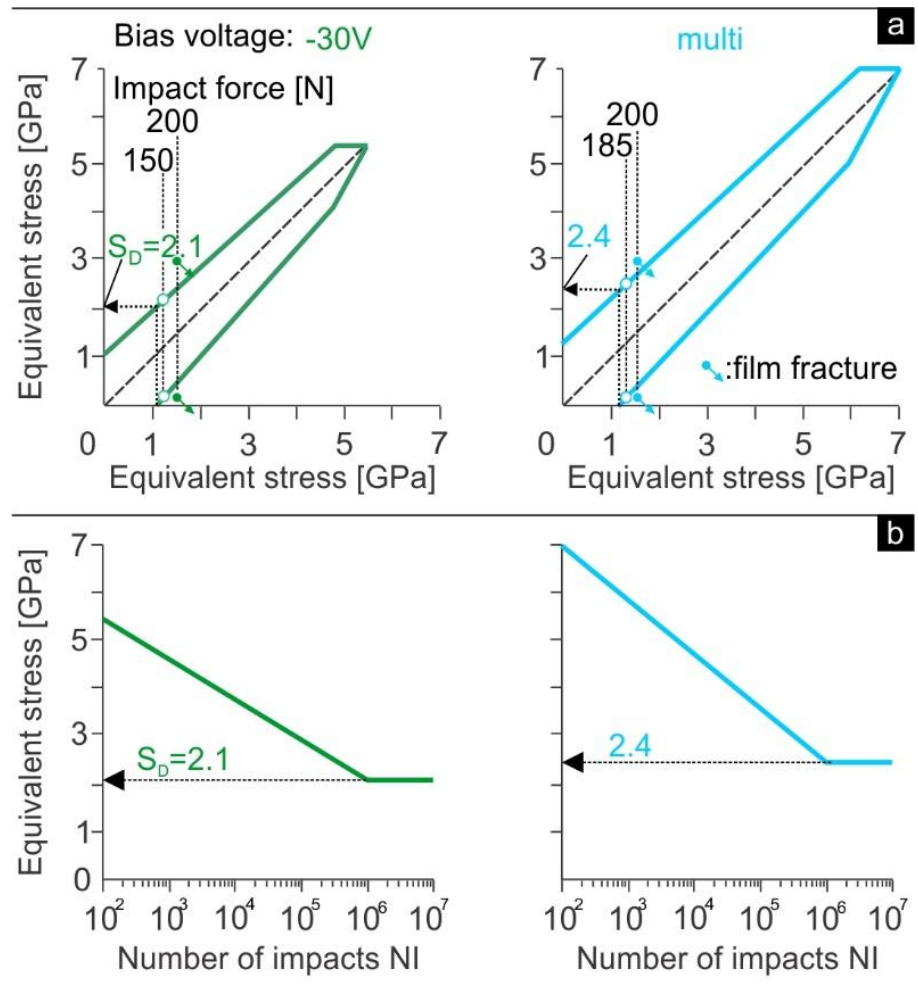

$\mathrm{S}_{\mathrm{D}}$ : fatigue endurance stress

Substrate: Sandvik R245-12 T3, HW-K05

Coating: PVD TiAIN, bias voltage $=-30 \mathrm{~V}, \mathrm{t} \approx 3 \mu \mathrm{m}$

Figure 4. (a) Created Smith-like diagrams of the applied coatings deposited at various bias voltages based on a FEM-supported determination of the developed film stresses during the loading and relaxation stage of the perpendicular impact test. (b) Established Woehler-like diagrams and the defined fatigue endurance stresses of the investigated coatings.

\subsection{Association of the CSR with A Critical Shear Stress (SFLS)}

Based on a method described in [13], the film adhesion can be quantified by a critical shear failure stress (SFLS). To predict SFLS in the coating-substrate region, a 3D-FEA model which simulates dynamically the inclined impact test was developed. The occurring SFLS in the coatingsubstrate interface affects the stresses resulting in the film during the operation of a coated component. In this way, they may lead to potential film material overloading and its cohesive failure. 
In right part of Figure 6, the effect of the shear failure stress percentile decrease on the film overloading during inclined impact test is shown. Moreover, the maximum stress percentile increase at lower CSR is estimated considering the ideal adhesion $(C S R=1)$ as reference. Thus, the maximum stress percentile increase at various CSR can be related to certain SFLS percentile decrease (see Figure 6). For example, when CSR amounts to about 0.1 or 0.01 , the SFLS percentile decrease amounts to 18 and $50 \%$, respectively, and a maximum film stress percentile increase of 4.5 and $16 \%$ develops in the corresponding cases.


Impact force $\mathrm{F}=90 \mathrm{~N}$, inclination angle $\theta=15^{\circ}$

\begin{tabular}{|c|c|c|}
\hline Bias voltage [V] & -30 & multi \\
\hline CSR [-] & 0.05 & 0.004 \\
\hline
\end{tabular}
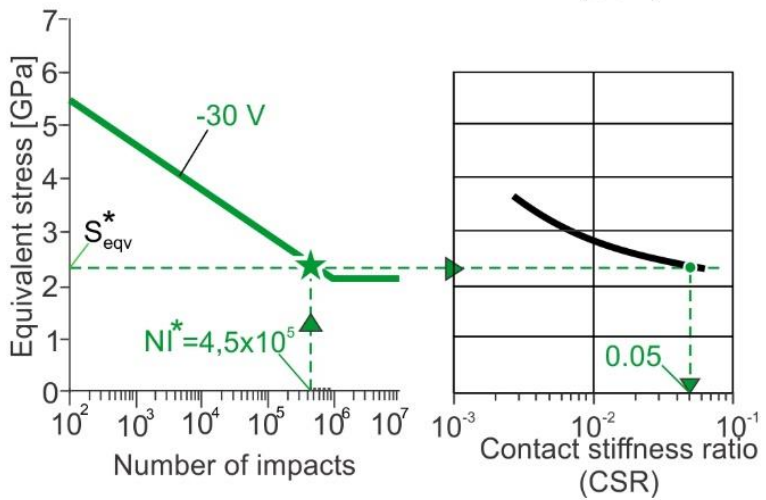

Substrate: Sandvik R245-12 T3, HW-K05 Coating: PVD TiAIN, $t \approx 3 \mu \mathrm{m}$

Figure 5. (a) Coating failure depth versus the number of impacts during the inclined impact tests on the investigated PVD films. (b) Determination of the contact stiffness ratios (CSR) quantifying the adhesion of the tested coatings. (c) FEM calculated equivalent stress distributions during the inclined impact test on the prepared coatings at $-30 \mathrm{~V}$ and multi-bias voltage possessing different adhesion strengths.

\section{Diamond Coating Interfacial Fatigue Strength}

Recently, a dynamic 3D-finite element method (FEM) thermo-mechanical model was developed for quantifying the temperature-dependent fatigue strength of nanocrystalline diamond (NCD) coating-substrate interface [14,15]. This model simulates dynamically the inclined impact test on NCD-coated cemented carbide inserts considering the temperature-dependent residual stresses in the NCD coating structure [16,17]. A fatigue damage of the NCD coating-substrate interface develops after a certain number of repetitive impacts depending on the applied impact load and temperature [14]. After the interface fatigue failure, the high compressive residual stresses of the NCD coating structure are released, and the detached coating hikes up at a certain maximum height (bulge formation). The critical impact forces for avoiding the fatigue failure of the NCD coating substrate interface, and the subsequent film detachment after $10^{6}$ impacts at various temperatures were determined by conducting inclined impact tests up to $400{ }^{\circ} \mathrm{C}$. Considering the critical impact forces and by using the mentioned FEA model, the related shear failure stresses in the NCD coatingsubstrate interface for triggering the coating detachment at various temperatures can be predicted. 
By using the previously-described FEM model [14,15], critical SFLS values for avoiding the fatigue damage of the NCD coating-substrate interface after $10^{6}$ impacts at various temperatures were estimated for different adhesion qualities. Figure 7a,b show characteristic calculated imprints at various SFLS values, after the ball indenter removal at a test temperature of $100{ }^{\circ} \mathrm{C}$. There is a remaining displacement of ca. $0.4 \mu \mathrm{m}$ in the improved NCD film adhesion case, at a SFLS equal to $0.42 \mathrm{GPa}$, after the ball removal due to substrate plastic deformation (see Figure 7a). A slightly decrease of SFLS from $0.42 \mathrm{GPa}$ to $0.41 \mathrm{GPa}$ in region I results in coating detachment and bulge formation. Thus, a SFLS of $0.42 \mathrm{GPa}$ is associated with the maximum operational stress permitted in the NCD coating-substrate interface for avoiding the coating detachment initiation at a temperature of $100{ }^{\circ} \mathrm{C}$. Related FEM calculations were carried out in the insufficient NCD film adhesion case at the same temperature of $100{ }^{\circ} \mathrm{C}$. The percentile decrease of the SFLS in the insufficient adhesion case compared to the improved one amounts to approximately $17 \%$.

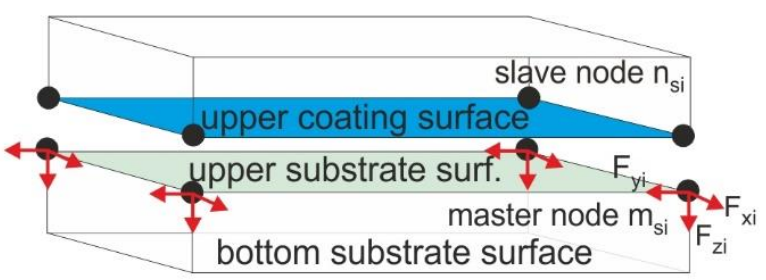

$\mathrm{F}_{\mathrm{xi}}, \mathrm{F}_{\mathrm{yi}}, \mathrm{F}_{\mathrm{zi}}$ : interface force components to master segment due to penetration of slave node $\mathrm{n}_{\mathrm{si}}$
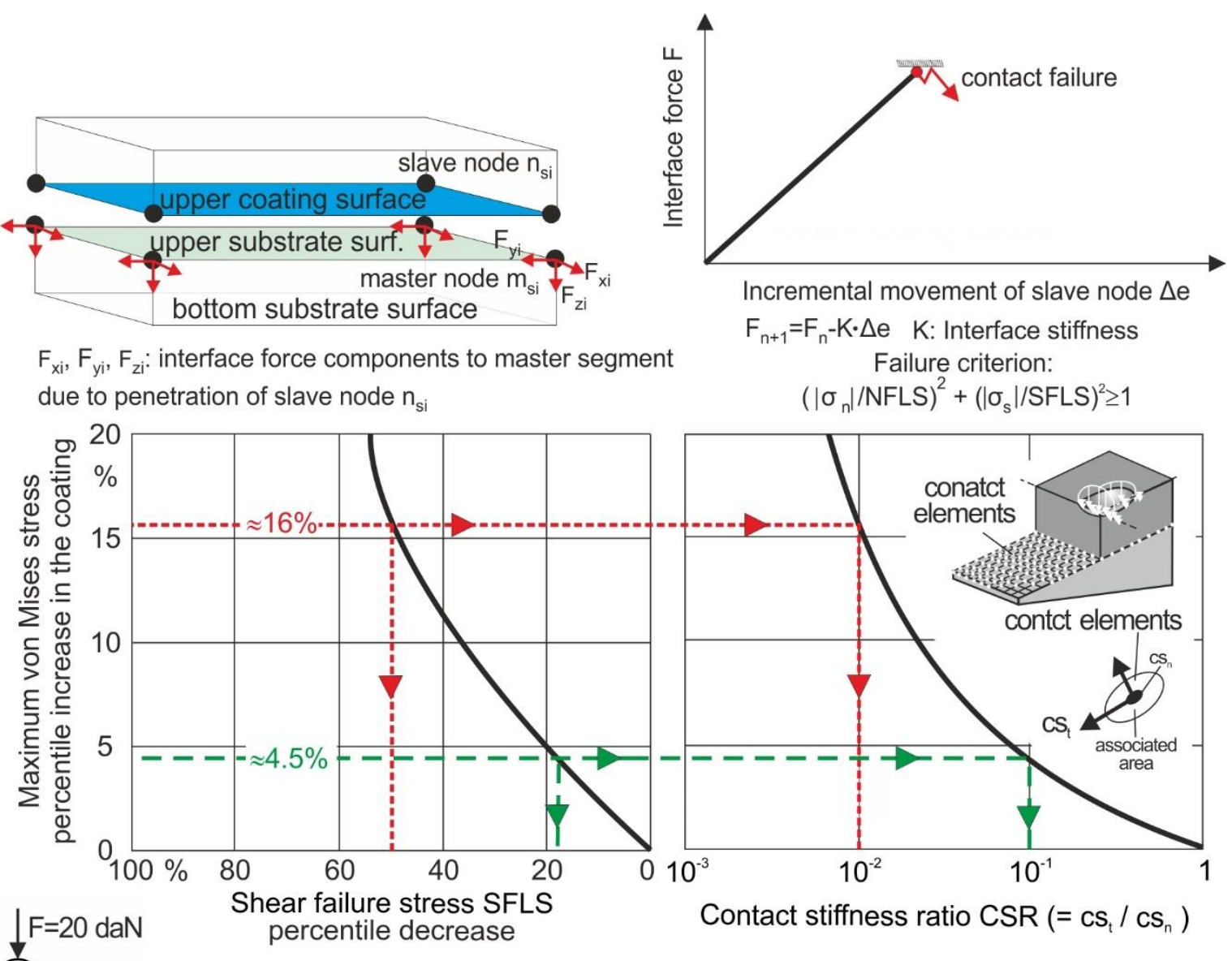

$\left(\mathrm{Ti}_{46} \mathrm{Al}_{54}\right) \mathrm{N}, \mathrm{t}=3.5 \mu \mathrm{m}, \mathrm{HW}-\mathrm{K} 05 / \mathrm{K} 20$, indenter: HW-K05, $\mathrm{R}_{\text {ball }}=2.5 \mathrm{~mm}, \mathrm{Vo}=32.5 \mathrm{~mm} / \mathrm{s}$

Figure 6. Relationship between contact stiffness ratio and shear failure stress percentile decrease.

The course of the FEM determined critical SFLS value for avoiding the initiation of NCD coating detachment versus the temperature after $10^{6}$ impacts for both adhesion cases are illustrated in Figure 8. The related functions describing the SFLS course versus the temperature are also shown in Figure 8. The predicted SFLSs decrease as the test temperature grows for both investigated adhesion cases. This fact can be attributed to the corresponding reduction of the critical impact load and to the diminished residual stresses at higher temperatures [14]. Moreover, SFLS decreases more intensely in the case of the insufficient adhesion compared to the improved one. 


\section{Conclusions}

The impact test is used since several years, among others, for characterizing coated surface's properties. In the paper, methodologies based on impact tests supported by FEA modelling for predicting the fatigue and adhesion properties of PVD and diamond coatings as well as characteristic application examples were presented. These contribute to the explanation of the operational behavior of the related parts, ascertaining the significance of this test method in the area of surface engineering.

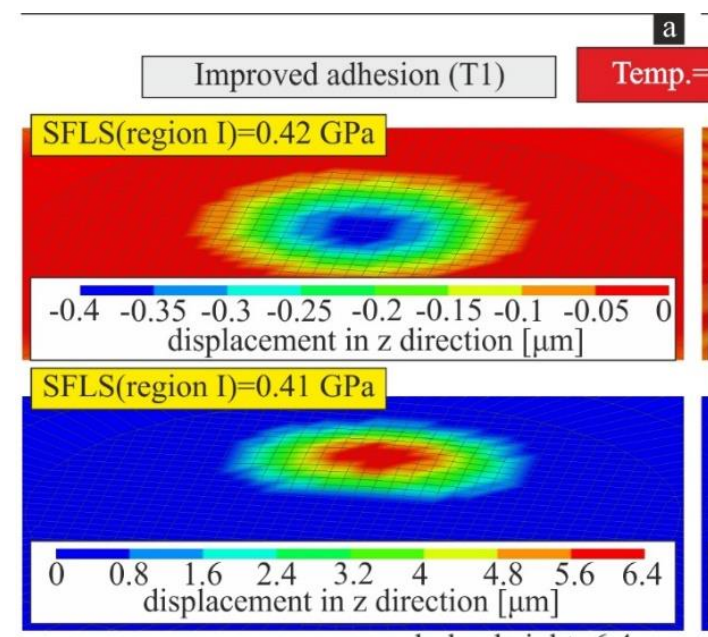

Al max. bulge height $=6.4 \mu \mathrm{m}$
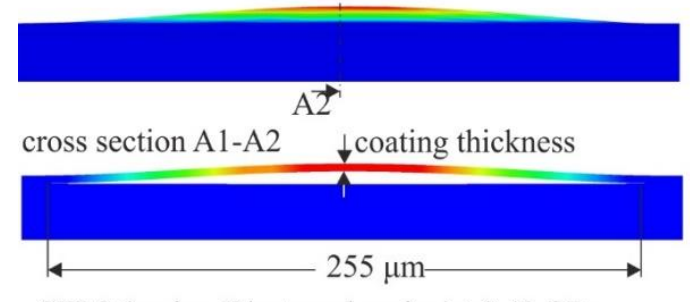

SFLS (region II/external region) $\geq 0.42 \mathrm{GPa}$

Critical impact force: $550 \mathrm{~N}\left(\mathrm{~V}_{\mathrm{o}}=82.7 \mathrm{~mm} / \mathrm{s}\right)$ b

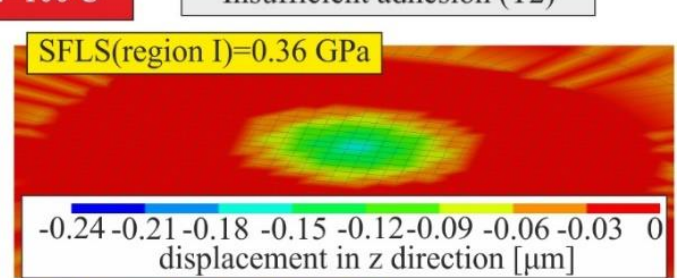

\section{SFLS(region I) $=0.34 \mathrm{GPa}$}

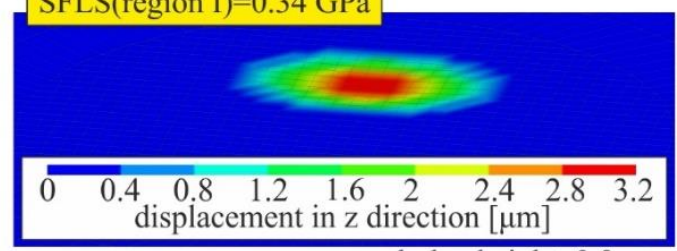

max. bulge height $=3.2 \mu \mathrm{m}$

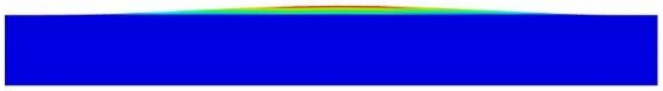

cross section $\mathrm{B} 1-\mathrm{B} 2$

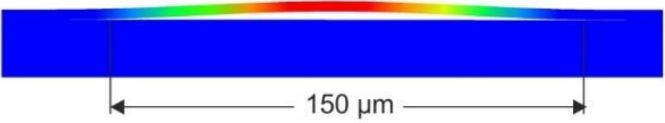

SFLS (region II/external region) $\geq 0.36 \mathrm{GPa}$

Critical impact force: $380 \mathrm{~N}\left(\mathrm{~V}_{\mathrm{o}}=52.3 \mathrm{~mm} / \mathrm{s}\right)$

NCD coating, thickness $=5 \mu \mathrm{m}$, substrate: HW-K05, indenter: HW-K05, $\mathrm{R}_{\text {ball }}=2.5 \mathrm{~mm}$

Figure 7. Characteristic NCD coated specimen's imprints at various SFLSs, after the ball removal at a test temperature of $100^{\circ} \mathrm{C}$ in the case of improved (a) and insufficient (b) adhesion.

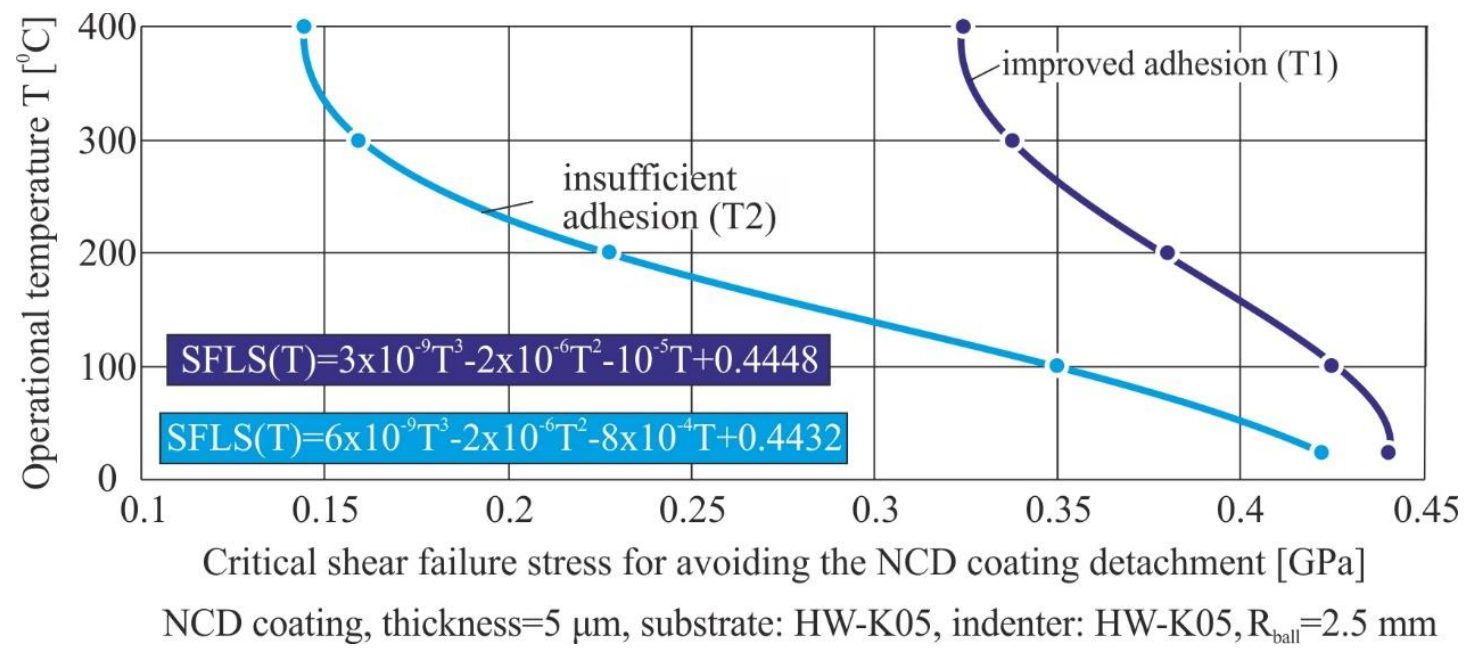

Figure 8. Effect of the operational temperature during inclined impact test on the critical SFLS for avoiding the interfacial fatigue damage of NCD coatings in the investigated adhesion cases. 
Conflicts of Interest: The authors declare no conflict of interest

\section{References}

1. Bobzin, K. High-performance coatings for cutting tools. CIRP J. Manuf. Sci. Technol. 2017, 18, 1-9, doi:10.1016/j.cirpj.2016.11.004.

2. Tönshoff, H.; Blawit, C.; Rie, K.; Gebauer, A. Effects of surface properties on coating adhesion and wear behaviour of PACVD-coated cermets in interrupted cutting. Surf. Coatings Technol. 1997, 97, 224-231, doi:10.1016/s0257-8972(97)00134-5.

3. Yamamoto, K.; Abdoos, M.; Ahmed, Y.S.; Stolf, P.; Beake, B.D.; Rawal, S.; Fox-Rabinovich, G.; Veldhuis, S.C. Cutting Performance of Low Stress Thick TiAlN PVD Coatings during Machining of Compacted Graphite Cast Iron (CGI). Coatings 2018, 8, 38, doi:10.3390/coatings8010038.

4. Bouzakis, K.-D.; Michailidis, N.; Skordaris, G.; Bouzakis, E.; Biermann, D.; M'Saoubi, R. Cutting with coated tools: Coating technologies, characterization methods and performance optimization. CIRP Ann. 2012, 61, 703-723, doi:10.1016/j.cirp.2012.05.006.

5. Beake, B.D.; Fox-Rabinovich, G.S.; Veldhuis, S.C.; Goodes, S.R. Coating Optimization for High Speed Machining with Advanced Nanomechanical Test Methods. Surf. Coat. Technol. 2009, 203, 1919-1925.

6. Constantinides, G.; Tweedie, C.A.; Holbrook, D.M.; Barragan, P.; Smith, J.F.; Van Vliet, K.J. Quantifying deformation and energy dissipation of polymeric surfaces under localized impact. Mater. Sci. Eng. A 2008, 489 1-, doi:10.1016/j.msea.2007.12.044.

7. Bouzakis, K.-D.; Vidakis, N.; David, K. The concept of an advanced impact tester supported by evaluation software for the fatigue strength characterization of hard layered media. Thin Solid Films 1999, 355, 322329, doi:10.1016/s0040-6090(99)00451-4.

8. Bouzakis, K.-D.; Maliaris, G.; Makrimallakis, S. Strain rate effect on the fatigue failure of thin PVD coatings: An investigation by a novel impact tester with adjustable repetitive force. Int. J. Fatigue 2012, 44, 89-97, doi:10.1016/j.ijfatigue.2012.05.010.

9. Coatings Testing Experts. Available online: www.impact-bz.com (access on 30 April 2020).

10. Bouzakis, K.-D.; Asimakopoulos, A.; Skordaris, G.; Pavlidou, E.; Erkens, G. The inclined impact test: A novel method for the quantification of the adhesion properties of PVD films. Wear 2007, 262, 1471-1478, doi:10.1016/j.wear.2007.01.027.

11. Bouzakis, K.-D.; Charalampous, P.; Skordaris, G.; Dimofte, F.; Ene, N.; Ehinger, R.; Gardner, S.; Modrzejewski, B.; Fetty, J. Fatigue and adhesion characterization of DLC coatings on steel substrates by perpendicular and inclined impact tests. Surf. Coatings Technol. 2015, 275, 207-213, doi:10.1016/j.surfcoat.2015.05.018.

12. Skordaris, G.; Bouzakis, K.-D.; Charalampous, P.; Kotsanis, T.; Bouzakis, E.; Bejjani, R. Bias voltage effect on the mechanical properties, adhesion and milling performance of PVD films on cemented carbide inserts. Wear 2018, 50-61, doi:10.1016/j.wear.2018.03.001.

13. Skordaris, G. Fatigue Strength of Diamond Coating-Substrate Interface Quantified by a Dynamic Simulation of the Inclined Impact Test. J. Mater. Eng. Perform. 2014, 23, 3497-3504, doi:10.1007/s11665-0141163-9.

14. Skordaris, G. Temperature-Dependent Fatigue Strength of Diamond Coating-Substrate Interface Quantified via the Shear Failure Stress. J. Mater. Eng. Perform. 2015, 24, 3335-3342, doi:10.1007/s11665-0151620-0.

15. Skordaris, G. Effect of the temperature dependent residual stresses of diamond coated tools with different adhesion qualities on their interfacial fatigue strength. J. Balk. Tribol. Assoc. 2016, 22, 1776-1786.

16. Woehrl, N.; Hirte, T.; Posth, O.; Buck, V. Investigation of the coefficient of thermal expansion in nanocrystalline diamond films. Diam. Relat. Mater. 2009, 18, 224-228, doi:10.1016/j.diamond.2008.10.016.

17. Lee, D.-G.; Fitz-Gerald, J.M.; Singh, R.K. Novel method for adherent diamond coatings on cemented carbide substrates. Surf. Coatings Technol. 1998, 100, 187-191, doi:10.1016/s0257-8972(97)00612-9.

(C) 2020 by the authors. Submitted for possible open access publication under the terms and conditions of the Creative Commons Attribution (CC BY) license (http://creativecommons.org/licenses/by/4.0/). 